Review began 02/02/2022 Review ended 02/07/2022 Published 02/10/2022

๑) Copyright 2022

Sahu et al. This is an open access article distributed under the terms of the Creative Commons Attribution License CC-BY 4.0. which permits unrestricted use, distribution, and reproduction in any medium, provided the original author and source are credited.

\section{Missed Intra-Orbital Wooden Foreign Body}

\author{
Sandip K. Sahu ${ }^{1}$, Priyadarshini Mishra ${ }^{1}$, Anjali Kharolia ${ }^{1}$ \\ 1. Ophthalmology, All India Institute of Medical Sciences, Bhubaneswar, Bhubaneswar, IND \\ Corresponding author: Sandip K. Sahu, drsandipsahu@yahoo.com
}

\begin{abstract}
Intra-orbital wooden foreign bodies (IOFB) are always a diagnostic challenge. Those are entered by unmarked trivial injuries, as in our case, may become even more difficult, and maybe notorious and remain quiescent for a long time, before presenting with a variety of complications. It may lead to a more diagnostic dilemma, which can especially occur with wooden foreign bodies (FB) due to the variable nature of radioimaging. The lack of clinical suspicion may lead to a series of errors both in diagnosis and management, subjecting the patient to unnecessary intervention. In this case report, we will describe a missed wooden foreign body that, after a long quiescent period, presented as an intra-orbital mass.
\end{abstract}

Categories: Ophthalmology, Environmental Health, Trauma

Keywords: intra orbital mass, diagnostic challenge, wooden foreign bodies, missed, intra orbital

\section{Introduction}

Orbital disease or morbidity is always a diagnostic challenge for the ophthalmologist. Intra-orbital foreign bodies (IOFB) mainly enter the orbit between the eye and the orbital walls, but may occasionally enter the orbit through the eye or through the paranasal sinus into the orbit. Wooden foreign bodies (FB) enter through the eyes. Some unmarked trivial injuries, as in our case, may be notorious and remain quiescent for a long time before presenting with a variety of complications. There will be a diagnostic dilemma in missed foreign bodies as usual imaging and other diagnostic procedures did not detect intra-orbit wood due to their radiolucent nature. We report an unusual case of an intra-orbital wooden foreign body.

\section{Case Presentation}

A 70-year-old male presented with left eye mild pain, watering, discharges with restricted eye movement for six months. History-taking was unremarkable, except for the community bath. On examination, his vision was $20 / 40$ with a senile cataract. The globe was intact, with mild ptosis, and restricted eye movement in all lateral gaze. Intra-ocular pressure (IOP) was normal, with regurgitation of pressure over the lacrimal sac.

Imaging was advised. A computed tomography (CT) scan of the left orbit in axial and coronal planes depicted a predominantly intraconal soft tissue density mass lesion measuring $2.5(\mathrm{AP}) \times 1.5(\mathrm{ML}) \times$ $1.5(\mathrm{CC}) \mathrm{cm}^{3}$ involving the medial rectus and posterior aspect of the superior rectus muscle with a probable diagnosis of metastasis, lymphoma, or other mass lesion. Thus, a contrast study or magnetic resonance imaging (MRI) was advised.

MRI revealed a well-defined T2 hypointense lesion in the left orbit involving the medial rectus and extending to the postero-medial aspect of the superior rectus, abutting the lateral part of the left optic nerve sheath. It was heterogeneously enhanced with contrast, pointing more towards an inflammatory origin (Figure 1). 


\section{Cureus}

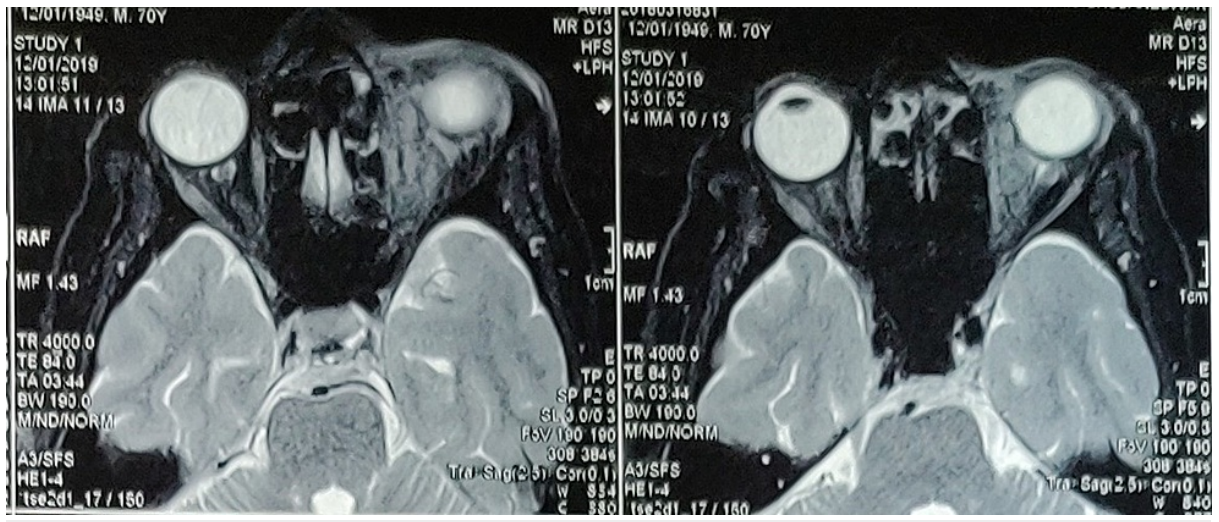

\section{FIGURE 1: MRI orbital axial T2 image}

Hypointense lesion in left orbit involving the medial rectus and extending to postero-medial aspect of superior rectus abutting the lateral part of left optic nerve sheath

Routine blood investigations were within the normal limit. As the patient did not have systemic diseases or symptoms of any malignancies, he was given a course of oral steroids in a tapering dose and an oral antibiotic. Although the pain subsided, the ocular motility did not improve (Figure 2A, 2B). Meanwhile, the patient underwent dacryocystectomy. Surgery was uneventful, but on the seventh post-operative day, an inflammatory mass (Figure 3A) at the medial canthus of the bulbar conjunctiva lateral to the caruncle was noticed. This time, we planned an excisional biopsy. On table as we started dissecting to our utter astonishment, a black mass started peeping from behind. After removal, clinically it was confirmed to be a wooden foreign body (Figure 3B) measuring $2.0 \times 0.2 \times 0.2 \mathrm{~cm}^{3}$ and sent for histopathology and culture.
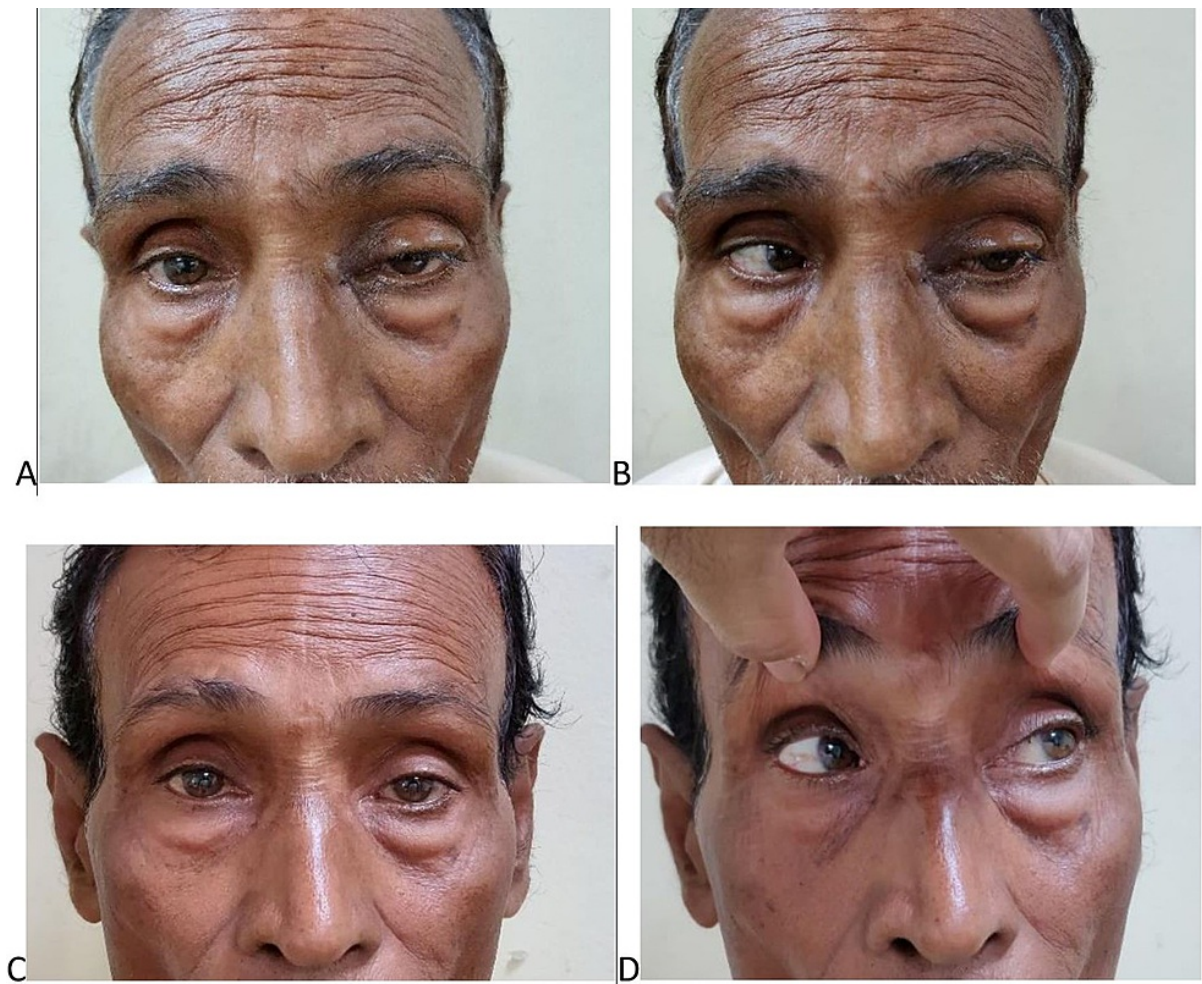

\section{FIGURE 2: Pre and post-operative images}

$(A, B)$ Pre-operative images of the patient in primary and lateral gaze and $(C, D)$ post-operative images of the patient in primary and lateral gaze 


\section{Cureus}
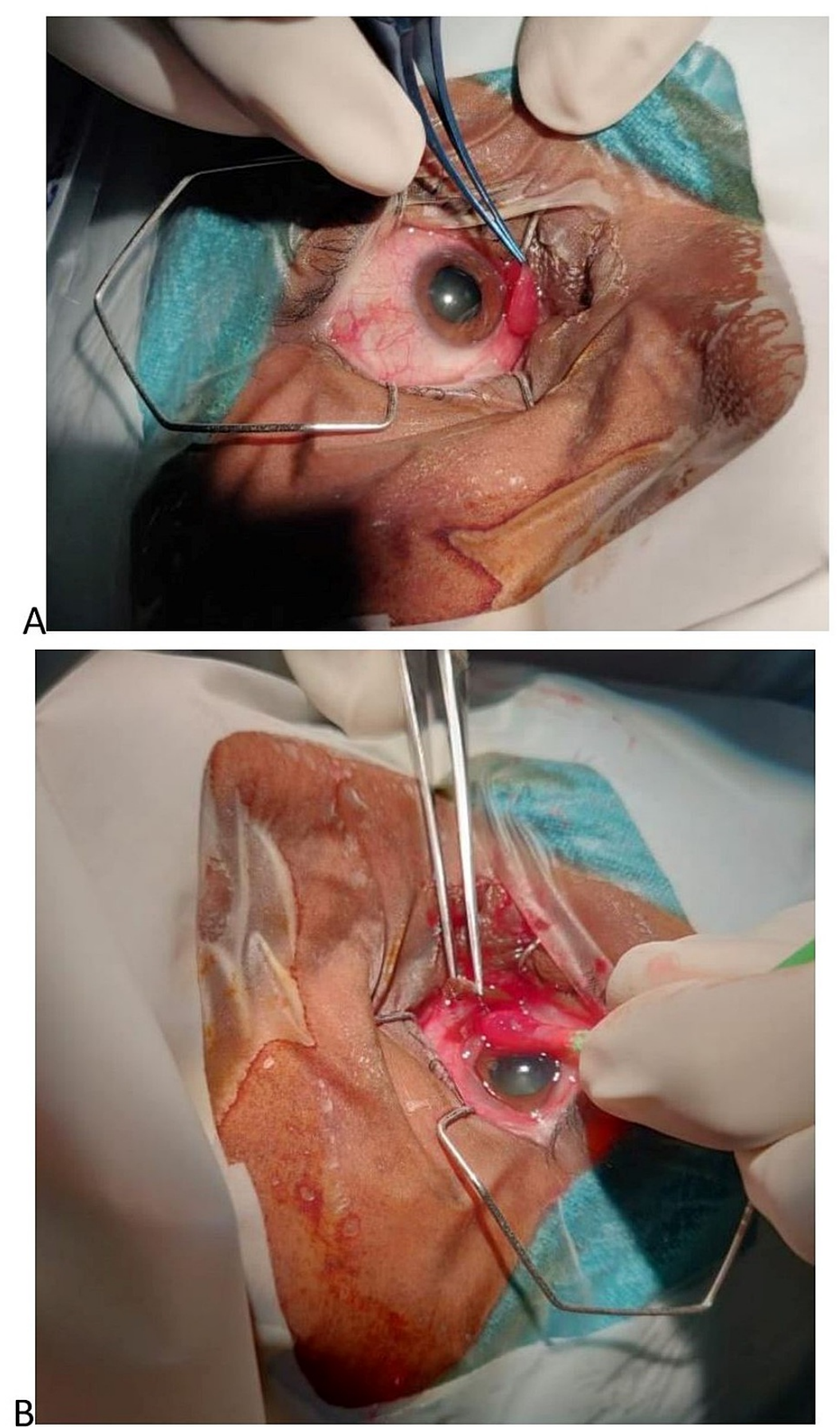

\section{FIGURE 3: Intra-operative images}

(A) Inflammatory mass at medial canthus on bulbar conjuctiva and (B) wooden foreign body after dissecting the inflammatory mass

On examination, the biopsy report of the inflammatory mass revealed a section measuring $0.5 \times 0.5 \times 0.2$ $\mathrm{cm}^{3}$ that shows fibrocollagenous tissue without any epithelial lining and contains edematous stroma, proliferated vascular channels with inflammatory cell infiltration consisting of predominantly plasma cells, lymphocytes, scattered eosinophils and neutrophils, and myofibroblasts seen. No evidence of granuloma, atypia or malignancy was seen in the section. There was no evidence of obliterative

thrombophlebitis/fibrosis. On follow-up after two weeks, the restriction of ocular muscles had improved and the ptosis receded (Figure 2C,2D).

\section{Discussion}


Depending on chemical composition, IOFB can be classified into (1) metallic, (2) nonmetallic, and (3) organic [1]. Among the three types, organic substances are not only much more difficult to detect on imaging but also pose a higher risk of complications because secondary infection and decay of the FB may cause severe inflammation [2]. Among organic substances, wooden FB provides an ideal environment for microorganism growth due to its organic nature and porous consistency [3]. Complications like orbital cellulitis, abscess formation, chronic discharge sinus, extraocular muscle damage, exophthalmos, and central nervous system (CNS) infection can occur [4].

Our case was presented with mild pain, redness, discharge, and restricted ocular motility. As a result, the main differential diagnoses were infective or inflammatory orbital pathology. Lacrimal sac pathology was an additional finding. With proper clinical evaluation, the radiological examination also failed to identify the presence of the wooden foreign body. Post-operative repeated history of trivial injuries during a bath at the pond throws light on a wooden foreign body that may remain inconspicuous and yet be able to show its hazardous effects by acting as a natural reservoir of micro-organisms. The mere capability to camouflage orbital tissues and air in B-scan, plain X-ray, and CT scan, makes it arduous to diagnose [5]. Like in our case, it caused an intense granulomatous reaction [6] that not only compromised the function of the superior rectus and medial rectus but also the levator palpebrae superioris by its compression effect on the superior division of the ophthalmic nerve. The impression from the CT scan broadened our horizons to include lymphoma and metastasis in our differential diagnosis. The T2 weighted contrast-enhanced MRI (CEMRI) showing a heterogeneously hypointense lesion helped in narrowing the diagnosis to an inflammatory mass. It forced us to rethink that the trauma may be with wooden or organic materials, and subsequently, the patient was started on oral antibiotics, suspecting a foreign body might still be present inside.

\section{Conclusions}

So, repeating leading questions to get a clue regarding the diagnosis is very essential. The normal appearance on the CT scan and USG does not rule out the possibility of a foreign body. At the same time, blind exploration of the orbit is not recommended for something suspected without positive proof of its position or even its existence. It is prudent to defer any surgical exploration until definite localizing signs become apparent. Such management offers a planned approach with minimal injury to orbital structures.

\section{Additional Information \\ Disclosures}

Human subjects: Consent was obtained or waived by all participants in this study. Conflicts of interest: In compliance with the ICMJE uniform disclosure form, all authors declare the following: Payment/services info: All authors have declared that no financial support was received from any organization for the submitted work. Financial relationships: All authors have declared that they have no financial relationships at present or within the previous three years with any organizations that might have an interest in the submitted work. Other relationships: All authors have declared that there are no other relationships or activities that could appear to have influenced the submitted work.

\section{References}

1. Sitaula S, Gautam V: Intraorbital wooden foreign body: a case report. J Kathmandu Med Coll. 2014, 3:11921.

2. Macrae JA: Diagnosis and management of a wooden orbital foreign body: case report . Br J Ophthalmol. 1979, 63:848-51. 10.1136/bjo.63.12.848

3. Tsaloumas MD, Potamitis T, Kritzinger EE: Two cases of retention of wooden foreign bodies in orbit of eye . Br Med J. 1998, 316:1363-4.

4. Ananth Kumar GB, Dhupar V, Akkara F, Praveen Kumar S: Foreign body in the orbital floor: a case report . J Maxillofac Oral Surg. 2015, 14:832-5.

5. Goldberg MF, Paton D: Ocular emergencies. Principle and Practice of Ophthalmology. Peyman GA, Sanders DR, Goldberg MF (ed): WB Saunders, Philadelphia; 1980. 2466.

6. Kidder GW, Montgomery CW: Oxygenation of frog gastric mucosa in vitro . Am J Physiol. 1975, 229:1510-3. 10.1152/ajplegacy.1975.229.6.1510 